\title{
Criatividade servindo linhas de fuga em duas histórias de invisíveis - um estudo CTS (Ciência, Tecnologia e Sociedade)
}

\section{Creativity creating an alternative path in two stories about the invisible ones - a STS (Science, Technology and Society) study}

\author{
Marcia de Oliveira Cardoso \\ Instituto Tércio Pacitti de Pesquisas e Aplicações Computacionais (NCE), Universidade \\ Federal do Rio de Janeiro (UFRJ). \\ marcia@nce.ufrj.br \\ orcid.org/0000-0002-0799-9377
}

Resumo. Em 2017 dois eventos enfatizaram a importância da preservação da memória da UFRJ, convidando a comunidade para uma reflexão sobre o fazer e saber cotidiano da instituição. Muitos destes saberes e fazeres ainda são invisíveis, cotidianos de um Lado B, quase sempre não divulgados, e não fazem parte de uma chamada "história oficial" - daqueles gerados em um mainstream. Neste grupo, estão os que, com criatividade, optam por caminhos alternativos para produzir um conhecimento localizado. Portanto, em comemoração aos 100 anos da UFRJ, este trabalho traz duas histórias que envolvem elementos heterogêneos e criatividade para produzir fato e artefato. Uma, é a história da construção de um cabo necessário para conectar um teclado musical a um computador; a outra, é a história dos malabarismos que foram necessários para o ensino de uma nova forma de edição de vídeos.

Palavras-chave: Estudos CTS. História das técnicas.História das ciências.

\begin{abstract}
In 2017 two events emphasized the importance of preserving UFRJ'S memory, inviting the community to reflect on the institution's daily activities and knowledge. Many of these knowledges and practices are still invisible, almost always undisclosed and are not part of a so-called "official story" - of those generated within a mainstream. In this group there are those who, with creativity, choose an alternative path to create local knowledge. Therefore, in commemoration of 100 years of UFRJ, this paper brings two stories that involve heterogeneous elements and creativity to produce facts and artifacts. One is the story of building a cable needed to connect a music keyboard to a computer; the other tells about all the juggling that was necessary to teach a new way of editing videos.
\end{abstract}


Keywords:STS studies. History of techniques. History of science.

Recebido: 01/10/2017 Aceito: 27/10/2017 Publicado: 06/11/2017

\section{Introdução - apresentando as histórias}

Em 2017, a Universidade Federal do Rio de Janeiro (UFRJ) foi palco de dois eventos diretamente relacionados com a história da própria instituição, que fará 100 anos em 2020. Os eventos incentivaram que os trabalhos inscritos procurassem refletir e debater sobre a construção histórica e cotidiana da UFRJ (SEMINÁRIO A UFRJ FAZ 100 ANOS, 2017), sinalizando a importância da preservação de documentos e depoimentos, dos "lugares de memória", dos artefatos e dos saberes e fazeres no cotidiano da vida universitária e da "representação dos indivíduos que se reconhecem como parte integrante do patrimônio cultural da UFRJ" (SEMINÁRIO MEMÓRIA, DOCUMENTAÇÃO e PESQUISA, 2017).

Empolgada com estes eventos, que de certa forma buscam, nos textos escritos e inscritos, dar historicidade à UFRJ, decidi apresentar duas histórias que ocorreram no Instituto Tércio Pacitti de Aplicações e Pesquisas Computacionais (NCE). Muitos dos saberes e fazeres cotidianos da universidade são ainda invisíveis - cotidianos de um lado B, um outro lado da questão, constituído de elementos heterogêneos, que surge das reações inesperadas (PAIVA et al., 2015). Porém, creio que estas histórias podem possibilitar um olhar para os que optaram por caminhos diferentes do estabelecido em uma chamada "história oficial", gerados no mainstream, e permitem apontar holofotes para o palco dos diversos atores humanos, quase sempre agentes coadjuvantes encontrados em suas linhas de fuga (MARQUES, 2014), ao seguirmos seus próprios caminhos para um conhecimento localizado, modificado e adaptado. São histórias onde a criatividade transborda, transforma posições e rearruma relações de poder (RIP et al., 1995) para além de enquadramentos obtidos a priori de um caminho dito universal.

\section{2. $O$ cabo adaptador MIDI}

O primeiro relato, da década de 1990, segue a trajetória do cabo MIDI Kit (ou cabo adaptador MIDI), necessário para conectar um teclado musical possuidor do padrão de transmissão digital chamado Musical Instrument Digital Interface (MIDI) a um microcomputador do tipo PC 486 da época. Esta é a história da construção coletiva deste adaptador, apresentando uma rede de atores heterogêneos, entre eles engenheiros, analistas de sistemas, computadores, teclados, cabos e programas de computador. Esta é uma história que procura seguir a primeira regra do método de Bruno Latour (1997, p. 13), que versa sobre a observação de fatos e máquinas durante a sua construção, sem 
nenhum preconceito sobre o que constitui o conhecimento, onde observamos o trabalho dos envolvidos, as incertezas e as escolhas que foram feitas.

Em 1989, consta que Moacyr de Paula, analista de sistemas do então Núcleo de Computação Eletrônica da Universidade Federal do Rio de Janeiro (NCE/UFRJ) estava trocando seu computador pessoal por um moderno PC 486, ideal para seus projetos em Computação Gráfica. Esta mudança também tornaria obsoleta sua interface MIDI da marca Roland, denominada MPU401, um periférico de conexão entre seu teclado e o computador, com a qual ele transformava sons em arquivos digitais. A solução para continuar este trabalho seria utilizar uma placa de som já instalada no seu novo computador, chamadaSound Blaster.Esta placa, embora incorporasse a tecnologia MIDI, necessitava de um acessório chamado cabo MIDI-Kit. Inexistente no Brasil, este cabo precisou ser importado dos Estados Unidos (EUA).

A história poderia parar aqui: com a importação do cabo Moacyr conseguiria conectar seu teclado ao novo computador e o cabo continuaria uma caixa-preta, um ponto estabilizado nesta rede. Mas havia um desenho,ou esquema, da especificaçãopara a montagem do MIDI-Kit na WEB eMoacyr desejava mais cabos para interagir com colegas músicos utilizando a mesma tecnologia. Porém, alguns dos componentes eletrônicos deste esquema não existiam no Brasil. Desta forma, Moacyr procurou o engenheiro eletrônico Diogo Takano, que trabalhava com estes componentes no NCE, sabendo que ele estava procurando novos produtos, simples e baratos, para uma empresa fabricante de cabos, conectores e equipamentos eletrônicos da época, chamada Lay-Cab, da qual era consultor. Segundo Latour (1987, p. 108) a primeira e mais fácil maneira de achar pessoas que acreditem imediatamente no fato, invistam no projeto ou comprem o protótipo é construir o objeto de uma forma que atenda aos interesses explícitos destas pessoas. Sendo assim, Moacyr convenceu o engenheiro, enfatizando a possibilidade de projetarem um cabo simples e de baixo custo, ainda não existente no Brasil, o que atenderia aos interesses de Diogo Takano. E após sua anuência, e uma análise dos componentes do esquema original do cabo MIDI-kit, Diogo Takano começou a testar componentes eletrônicos substitutos (diodos, transistores, entre outros), uma vez que a importação dos componentes necessários inviabilizaria um produto barato. E os novos componentes, muitas vezes obtidos no descarte tecnológico da empresa $L a y$-Cab, formaram uma nova rede de elementos heterogêneos, fazendo surgir um novo esquema. Para Latour (1987, p. 124), escolhas devem ser feitas pois não podemos ligar elementos entre si de forma aleatória - escolher significará rearrumar as alianças e estabelecer novas relações. E no desenvolver do cabo, é possível identificar o fortalecimento e o enfraquecimento das ligações (alianças) entre os elementos, como resultante dos caminhos escolhidos: Moacyr, Diogo Takano e o esquema original, primeiramente; Diogo Takano e o esquema criado para obter baixo custo, posteriormente, e o abandono do esquema original. Assim, aos poucos, a relação de Moacyr com o cabo só se estabelece quando ele precisa de um novo MIDI-kit para seus colegas músicos, ou é acionado para testar os protótipos. E desta nova associação, na estabilidade do cabo, surgem alguns novos elementos como a confecção de uma extensão no Kit para o uso simultâneo de joystick e do cabo MIDI, tamanho ideal do 
cabo para uso em estúdio de gravação, que foram ou não considerados nas escolhas de Diogo Takano, agora porta-voz (LATOUR, 1987, p. 71) da especificação e do esquema do MIDI-kit.

Quer saber como termina esta história? Só posso terminá-la provisoriamente, informando que o cabo foi comercializado pela empresa $L a y-C a b$. Se ele ainda é vendido, esta é uma outra história.

\section{Ensinando a edição não linear de vídeos}

Esta história ocorreu em meados da década de 1990. Ela versa sobre a adoção de computadores como ferramentas auxiliares que, aliados aos sistemas de edição não linear, estabeleceram uma mudança nos processos de produção de vídeos, incorporando elementos, humanos ou não, e linguajar da área de informática (aqui cito programadores, técnicos, arquivos de dados, formatos, compressão, digitalização) até então não utilizados na arte de edição de vídeos - as empresas produtoras de vídeos utilizavam o processo de edição linear. Se observarmos que hoje os sistemas de edição não linear estão bastante naturalizados nesta produção, nem imaginamos o quanto a introdução desta tecnologia possa ter sido complexa. Afinal, se a tecnologia estava pronta e importada não deveria ser simplesmente utilizada? $\mathrm{E}$ o auxílio no desenvolvimento de novas técnicas e a melhora da qualidade do vídeo, facilitados pela edição não linear de vídeos, não bastariam?

A análise da adoção da edição não linear, sobre uma ótica construtivista (RIP et al., 1995), pode ser conceituada não como uma força independente que atuou sozinha, instalando-se sem critérios, mas como uma tecnologia que foi introduzida através de movimentos complexos, onde a sociedade interage, ajusta-se, empodera-se e modifica a própria tecnologia. Vendo sobre esta lente, perguntas sobre quem usa, quem é privilegiado, quem perde, quais as relações de poder e quais as diferenças geradas nos movimentos da introdução da tecnologia podem ser respondidas. Desta forma, na adoção de sistemas de edição não linear para vídeos,poderíamos levantar algumas controvérsias, quanto à forma de trabalho nas empresas produtoras, quanto à transformação na carreira dos editores, ou até mesmo o descortinar de opções implementadas pelos programas de computadores. Neste sentido, ainda podemos perguntar: como resolver as dificuldades de operar o computador? Como encarar as novas terminologias?

Editar um vídeo é basicamente selecionar um determinado material gravado (material bruto) e juntá-lo em um único material. A edição linear utiliza os equipamentos de uma ilha de edição para escolher do material bruto, que pode estar gravado em fitas distintas, os segmentos que serão gravados no material resultante, chamado de fita master. Além disso, os procedimentos de seleção e cópia do material bruto é feito sequencialmente ou linearmente, isto é, o primeiro segmento do material é copiado, seguido do segundo e assim por diante, o que torna quase impossível reordenar os segmentos. Se alguma modificação for necessária, deve-se efetuar a gravação da fita master novamente. $\mathrm{Na}$ 
edição não linear, o processo de seleção e cópia do material bruto começa com a digitalização dos vídeos, que são transferidos para o disco rígido do computador. $\mathrm{O}$ programa de edição não linear, inicialmente desenvolvido a partir das experiências de profissionais produtores de filmes, também recria na tela do computador alguns dos principais botões de operação dos equipamentos de uma ilha de edição linear e suas ferramentas. O programa tem como principal característica o timeline, ou janela de construção, onde o editor tem uma visão geral dos segmentos (agora chamados clips). Nesta janela é construída a sequência de vídeos que irá constituir o material master. Estas particularidades do programa, deveriam preparar o profissional editor de vídeo para a transição entre os dois modos de edição (OHARIAN, 1993, p. 299), uma vez que havia no programa uma representação do usuário produzida por especialistas (os dos filmes) (AKRICH, 1995, p. 174). Mas na prática, a mudança da ilha de edição para o computador trouxe dificuldades que deveriam ser resolvidas por quem desejava disseminar o uso da edição não linear.

Uma primeira dificuldade na adoção da edição não linear pelos profissionais das empresas produtoras de vídeos, seria a utilização do mouse. O profissional da edição linear possuía pouco ou nenhum conhecimento na área de informática e muitos ignoravam o computador como ferramenta de trabalho. Portanto, a dificuldade do manuseio do mouse precisou ser superada através de estratégias, como a utilização de jogos de computador básicos (jogo de cartas solitário, por exemplo), para convencer os editores a fazerem uso do novo sistema. A segunda dificuldade foi a grande variedade de verbetes em inglês e de novas terminologias (como, por exemplo, as dos formatos Audio Video Interleave (AVI) e Moving Picture Experts Group (MPEG)). Neste caso, em seus treinamentos, as revendedoras de equipamentos optaram por ensinar apenas o significado dos verbetes geradores de alguma ação significativa na edição. É interessante também perceber que alguns verbetes foram "aportuguesados", como é o caso do próprio verbo "to render" (traduzir, interpretar) que se transformou em renderizar (com o acréscimo também do substantivo renderização).

Aqui é possível resumir as mudanças em curso: além das transformações do editor, que deveria esquecer anos de refinamento técnico do mundo linear, houve também um rearranjo dos papéis dos envolvidos. Antes, na edição linear de vídeo havia, em geral, o especialista em vídeo, o especialista em áudio e o operador de caracteres, executando tarefas distintas e orientados pelo diretor de artes. A adoção da edição não linear concentrou as fases de edição em um só ambiente, onde o operador do programa navegava em todos os papéis. Antes, a construção do vídeo estava centrada na qualidade dos equipamentos da ilha de edição linear e os clientes procuravam a produtora com melhores equipamentos. Com a edição não linear, a construção empoderou quem utilizava o programa, uma vez que não existem diferenças significativas na qualidade digital (que simulava os equipamentos). Dessa forma, os clientes passaram a procurar as produtoras pela qualidade do operador do programa.

Por fim, a introdução da edição não linear fortaleceu a ligação dos computadores com os vídeos e permitiu o aparecimento de um grupo especialista em informática que, apto 
para lidar com a tecnologia, se posicionou na rede através da oferta de cursos de edição. Na UFRJ, o NCE também atuou neste grupo, com cursos ministrados pelo responsável pelo laboratório de Multimídia, Moacyr de Paula. Em 1999, após o término do terceiro curso, um levantamento baseado nas fichas de inscrição dos cursos indicou que uma boa parte dos alunos era formada por profissionais de áreas não ligadas à produção vídeos, mas que desejavam produzir seus próprios materiais.

E o que aconteceu com os especialistas da edição linear de vídeo? Esta é uma próxima história.

\section{Fatos e artefatos no cotidiano da UFRJ}

Os dois eventos que ocorreram na UFRJ, o Seminário a UFRJ faz 100 anos (2017) e o Seminário memória, documentação e pesquisa (2017), destacaram a importância da preservação da história cotidiana e patrimonial da universidade. De acordo com o então Reitor, Roberto Leher, o estabelecimento de um futuro para a universidade também depende de se "pensar a história" que, por sua vez, pode ser compreendida pela preservação de documentos e depoimentos dos indivíduos que fazem parte desta história (UFRJ, 2017). De fato, se observarmos o cotidiano da instituição certamente iremos encontrar os fatos e artefatos capazes de nos fazer compreender o seu funcionamento atual e os caminhos escolhidos no fazer da universidade. Neste sentido, espero que poder dar voz aos que participam desse cotidiano, alguns invisíveis, tal qual explorado nas histórias do MIDI kit e da adoção não linear de vídeos, possa contribuir na constituição de um conhecimento localizado, adaptado e criativo, que assume um lugar de memória na UFRJ.

Por fim, destaco que as histórias aqui representadas geraram novos desdobramentos e enquadramentos que poderiam gerar novos trabalhos na construção histórica da UFRJ. Um desses desdobramentos, por exemplo, permitiu que Moacyr ministrasse aulas sobre o uso do MIDI e sintetizadores e sobre edição não linear de vídeo para alunos, servidores técnico-administrativos e docentes da UFRJ, através dos chamados cursos livres do NCE. Por sua vez, o curso de edição não linear proporcionou a criação da antiga TVUFRJ, uma TV online, que agrupou diversas iniciativas como a TV online do Laboratório Didático do Instituto de Física (Ladif), a da Escola de Comunicação, a da COPPEAD, a dos projetos das Faculdades de Economia e Medicina, e a dos Conselhos Universitários.

\section{Referências}

AKRICH, M. User Representations: Pratices, Methods and Sociology. In:Managing Technology in Society.The approach of Constructive Thecnology Assessment. Pinter Publishers. 1995. p. $167-184$. 
LATOUR, B. Science in action. How to follow scientists and engineers through society. Cambridge, Massachusetts: Harward University Press, 1987.

MARQUES, I. C. Os cientistas têm conhecimentos; Os outros têm crenças. Como se escapa deste grilhão epistemológico? In: SCIENTIARUM HISTÓRIA, VII, 2014, Rio de Janeiro. Anais eletrônicos [...] Rio de Janeiro: UFRJ, 2014. Disponível em: $<$ http://www.hcte.ufrj.br/downloads/sh/sh7/SH/trabalhos.html $>$. Acesso em: 8 abr. 2020.

OHANIAN, T. A., Digital Nonlinear Editing - New Approaches to Editing Film and Video. Focal Press. 1993.

RIP, A.; MISA, T. J.; SCHOT, J. Managing Technology in Society -The approach of Constructive Thecnology Assessment. Pinter Publishers. 1995.

PAIVA, E.N.; CARDOSO, M. O.; DIAS, L. R.; PAIVA, T. M. Como pesquisar COM Maria do Socorro. In: SIMPÓSIO NACIONAL DE CIÊNCIA, TECNOLOGIA E SOCIEDADE ESOCITE.BR/TECSOC, VI, 2015, Rio de Janeiro. Anais eletrônicos [...]. Rio de Janeiro: UFRJ, 2015. Disponível em: $<$ https://www.rio2015.esocite.org.br/site/anaisarquivoresumo?MODALIDADE=6\#E $>$. Acesso em: 30 set. 2017.

SEMINÁRIO A UFRJ FAZ 100 ANOS, 2017, Rio de Janeiro. Tema: História, Desenvolvimento e Democracia. Seminário [...]. Rio de Janeiro: UFRJ, 2017. Disponível em <https://conferencias.ufrj.br/index.php/sufrj/sufrjcem>. Acesso em: 30 set. 2017.

SEMINÁRIO MEMÓRIA, DOCUMENTAÇÃO e PESQUISA, VIII., 2017, Rio de Janeiro. Tema: Documentação e Pesquisa: A Universidade e a sua diversidade patrimonial: memória, história, cultura e arte. Seminário [...]. Rio de Janeiro: UFRJ, 2017. Disponível em: $<$ https://memoria.sibi.ufrj.br/index.php/seminarios/viii-seminariomemoria-documentacao-e-pesquisa-a-universidade-e-a-sua-diversidade-patrimonialmemoria-historia-cultura-e-arte>. Acesso em: 30 set. 2017.

UFRJ completa 97 anos debatendo história desenvolvimento e democracia. Notícias UFRJ. Rio de Janeiro, 2017. Disponível em: <https://ufrj.br/noticia/2017/08/31/ufrjcompleta-97-anos-debatendo-historia-desenvolvimento-e-democracia $>$. Acesso em 30/09/2017. 